\title{
Saxatilin, a Snake Venom Disintegrin, Suppresses TNF- $\alpha$-induced Ovarian Cancer Cell Invasion
}

\author{
Dong Seok Kim, Yoon-Jung Jang, Ok-Hee Jeon and Doo-Sik Kim* \\ Department of Biochemistry, College of Science, Yonsei University, Seoul 120-749, Korea
}

Received 30 November 2006, Accepted 15 December 2006

\begin{abstract}
Saxatilin is a disintegrin known to inhibit tumor progression in vivo and in vitro. The role of saxatilin in cancer cell invasion was examined by a modified Boyden chamber assay in MDAH 2774 human ovarian cancer cell line. Saxatilin (50 $\mathrm{nM})$ significantly inhibited cancer cell invasion induced by tumor necrosis factor- $\alpha$ (TNF- $\alpha$ ). Saxatilin also reduced MMP-9 mRNA levels in cancer cells in a dosedependent manner. In addition, TNF- $\alpha$-induced MMP-9 activity was reduced by the treatment of saxatilin. These results indicate that transcriptional regulation of MMP-9 is an important mechanism for the tumor suppressive effects of saxatilin in MDAH 2774 human ovarian cancer cells.
\end{abstract}

Keywords: Disintegrin, Invasion, MMP-9, Ovarian cancer, TNF- $\alpha$

\section{Introduction}

Ovarian cancer is thought to metastasize into the peritoneal cavity and other organs at an early stage of the disease (Ellerbroek et al., 1999). During metastasis, reorganization of the extracellular matrix (ECM) and angiogenesis are key steps for migration and invasion of cancer cells (Davidson et al., 2003). ECM degradation is mainly regulated by gelatinases such as matrix metalloproteinase-2 (MMP-2) and matrix metalloproteinase-9 (MMP-9), which also have a critical role in angiogenesis and cancer proliferation in ovarian carcinomas (Roomi et al., 2006).

MMPs are a large family of proteins regulating cell survival, matrix remodeling, angiogenesis, and cell signaling (Sternlicht et al., 2001). MMP-9 (also known as gelatinase B) is an $89 \mathrm{kDa}$ protein which is important for tumor metastasis,

\footnotetext{
*To whom correspondence should be addressed.

Tel: 82-2-2123-2700; Fax: 82-2-312-6027

E-mail: dskim@yonsei.ac.kr
}

and has roles in the immune system and central nervous system (Opdenakker et al., 2001). Elevated MMP-9 expression is often correlated with malignancy of ovarian epithelial cancers whose progression is dependent on migration through the surrounding ECM (Davidson et al., 1999; Rauvala et al., 2005). MMP-9 is regulated by several mechanisms: transcriptional regulation, post-translational activation, and regulation by tissue inhibitors of metalloproteinase (TIMP) (Bjorklund et al., 2005). Appropriate manipulation of MMP-9 activity has been suggested as a cancer treatment preventing tumor metastasis and angiogenesis (Troussard et al., 2000).

Integrins are heterodimeric receptors critical in both cellcell interaction and cell adhesion to ECM, and regulate cell survival, growth, migration, and invasion (Hood et al., 2002). Integrins form over 25 combinations of $18 \alpha$ and $8 \beta$ subunits that determine ligand specificity (Bjorklund et al., 2005). When integrins bind their ligands, they initiate signal transduction into the cell in response to the extracellular environment. They also take part in signal transduction from in to out by modulating their affinity to ligands such as fibrinogen (Ginsberg et al., 2005). Integrins are known to regulate the activity of MMPs during tumor progression by modulating gene expression, activation, and localization (Bjorklund et al., 2005). Thus, disintegrin, as an integrin antagonist, is considered to be a potent tumor suppressing agent, along with integrin blocking antibodies and peptide.

Saxatilin is a monomeric disintegrin containing the tripeptide sequence Arg-Gly-Asp, a typical binding motif of adhesive proteins such as glycoprotein IIb-IIIa of platelets and $\alpha_{v} \beta_{3}$ integrin of endothelial cells (Hong et al., 2002). Besides inhibiting platelet aggregation, saxatilin is known to inhibit angiogenesis and melanoma pulmonary metastasis in a mouse model (Kim et al., 2006). We have previously reported that a very low concentration of saxatlin $(50 \mathrm{nM})$ suppresses interleukin-8 (IL-8) gene expression at the transcriptional level (Kim et al., 2007). We have postulated that the antiangiogenic and anti-metastatic activity of saxatilin might be due to the modulation of genes associated with migration and invasion of tumor cells. In this report, we demonstrate that 
saxatilin suppresses MMP-9 gene expression, reducing cell invasion in MDAH 2774 human ovarian cancer cells.

\section{Materials and Methods}

Cell culture and reagents. The human ovarian cancer cell line MDAH 2774 was obtained from American Type Culture Collection (ATCC) and grown in DMEM medium with $10 \%$ FBS, $25 \mathrm{mM}$ HEPES, $100 \mathrm{U} / \mathrm{ml}$ of penicillin, and $100 \mathrm{mg} / \mathrm{ml}$ of streptomycin. All culture reagents were purchased from Life Technologies.

RNA isolation and Reverse-transcription PCR analysis. After cells were treated with the indicated concentrations of saxatilin for $4 \mathrm{~h}$, total RNA was extracted with a MicroRNA Isolation Kit (Stratagene) as previously described (Choi et al., 2006). Total RNA was reverse-transcribed in the first-strand synthesis buffer containing oligo(dT) primer, StrataScript ${ }^{\mathrm{TM}}$ reverse transcriptase, dNTPs, and RNase inhibitor at $42^{\circ} \mathrm{C}$ for $1 \mathrm{~h}$. The cDNA was subjected to a standard PCR reaction for 25 cycles using the following primer sets: Actin forward 5'-GGG TCA GAA GGA TTC CTA TG-3', reverse 5'-CCT TAA TGT CAC GCA CGA TTT-3'; MMP-9 forward 5'-CAC TGT CCA CCC CTC AGA GC-3', reverse 5'GCC ACT TGT CGG CGA TAA GG-3'; bFGF forward 5'-CCC GAC GGC CGA GTT GAC-3', reverse 5'-CAC ATT TAG AAG CCA GTA ATC T-3'. PCR products were resolved on a $1 \%$ agarose gel and visualized with UV light after staining with ethidium bromide.

Gelatin zymographic assay. MDAH 2774 cells were incubated with TNF- $\alpha(10 \mathrm{ng} / \mathrm{ml})$, VEGF $(10 \mathrm{ng} / \mathrm{ml})$, and EGF $(10 \mathrm{ng} / \mathrm{ml})$ for $24 \mathrm{~h}$ under serum-free conditions in the presence or absence of various concentrations of saxatilin. The cell culture medium was analyzed for proteins with gelatinolytic activity by identification of substrate lysis in $7.5 \%$ SDS-polyacrylamide gels containing $2 \mathrm{mg} /$ $\mathrm{ml}$ gelatin. Gels were washed with $2.5 \%$ Triton $\mathrm{X}-100$ for $1 \mathrm{~h}$ and incubated for $16 \mathrm{~h}$ at $37^{\circ} \mathrm{C}$ in $50 \mathrm{mM}$ Tris- $\mathrm{HCl}, \mathrm{pH} 7.5$ containing $10 \mathrm{mM} \mathrm{CaCl}_{2}$. Gels were stained with Coomassie Brilliant Blue R$250(0.2 \%)$ in $40 \%$ methanol and $10 \%$ acetic acid.

MMP activity assay. The gelatinolytic proteinase activity of MMPs in cultured supernatants was determined by enzyme-linked immunosorbent assay (ELISA) after incubating $1 \times 10^{6}$ cells in $1 \mathrm{ml}$ of serum-free medium containing TNF- $\alpha(10 \mathrm{ng} / \mathrm{ml})$ in the presence or absence of saxatilin $(50 \mathrm{nM})$ for $24 \mathrm{~h}$. The supernatant was analyzed to estimate net gelatinase activity using MMP Collagenase Activity Assay Kit (CHEMICON) according to the manufacturer's instructions.

Cancer cell invasion assay. The invasion assay was carried out as previously described (Hong et al., 2002) with some modifications. Briefly, polycarbonate filters were coated with $10 \mathrm{mg}$ of Matrigel and placed in a transwell chamber. Serum-free medium was placed in the lower compartment of the chamber with or without $10 \%$ fetal bovine serum (FBS). Cell suspensions $\left(3 \times 10^{5}\right)$ in DMEM medium without FBS were loaded into the upper compartment of the chamber in the presence of saxatilin $(50 \mathrm{nM})$ or TNF- $\alpha(10 \mathrm{ng} / \mathrm{ml})$.
After incubation for $24 \mathrm{~h}$ at $37^{\circ} \mathrm{C}$, the filters were fixed with methanol and the cells invading through the basement membrane were counted.

\section{Results and Discussion}

Neoplastic cells tend to induce endothelial cells to migrate and invade surrounding tissues during tumor metastasis. During metastasis, cancer cells undergo several processes such as proliferation, matrix remodeling, invasion, migration, and differentiation. Integrins are known to play a critical role in these physiological events by regulating cell/cell interactions and cell/ECM adhesion both of which determine the invasiveness of cancer cells (Hood et al., 2002).

There are several reports that integrin signaling is associated with MMP expression or cell migration. Fibronectin induces MMP-9 expression through AP-1 activation in human lung carcinoma cells (Han et al., 2006). Moreover, contortrostatin, a homodimeric disintgrin containing RGD sequences, mimics the intracellular signaling evoked by fibronectin (Schmitmeier et al., 2005). Alternagin-C, a disintegrin-like protein from snake venom, even induces neutrophil chemotaxis with a potency similar to the classic neutrophil chemoattractant Nformyl-methionyl-leucyl-phenylalanine (Mariano-Oliveira et $a l ., 2003$ ). The effects of these disintegrins are distinguishable from traditional disintegrins (such as echistatin), which need micromolar concentrations to exert their physiological effects on endothelial cells (Schmitmeier et al., 2005).

Saxatilin, a disintegrin derived from snake venom, was introduced as an inhibitor of platelet aggregation by antagonizing integrin $\alpha_{\mathrm{II}} \beta_{3}$ on platelets and integrin $\alpha_{\mathrm{v}} \beta_{3}$ on the surface of endothelial cells (Hong et al., 2002). Furthermore, it is reported that saxatilin inhibits tumor metastasis in a mouse model (Kim et al., 2006). Recently, we reported that low concentrations of saxatilin inhibits ovarian cancer cell proliferation by suppressing IL-8 expression, implying that saxatilin can directly influence the expression of genes associated with tumor progression. In this study, saxatilin is shown to have a strong effect on MMP-9 expression and invasiveness in a human ovarian cancer cell line.

A matrigel invasion assay was employed to investigate the role of saxatilin in the invasiveness of the MDAH 2774 ovarian carcinoma. Saxatlin or TNF- $\alpha$ was present in the upper chamber while FBS was used as chemoattractant in the lower chamber. TNF- $\alpha$, a regulator of many angiogenic genes including MMP-9 (Thommesen et al., 2005; Cordiali-Fei et al., 2006), induced cell invasion as shown in Fig. 1. This cell invasion was reduced more than $80 \%$ in the presence of 50 $\mathrm{nM}$ saxatilin. One possibility is that saxatilin inhibited the ovarian cancer cell invasion by regulating integrin-mediated signaling. However, disintegrins are also known to reduce cell migration by physically blocking integrin. We note that halfmaximal inhibition of vitronectin-induced smooth muscle cell migration is obtained with $2.6 \mathrm{mM}$ of saxatilin (Hong et al., 


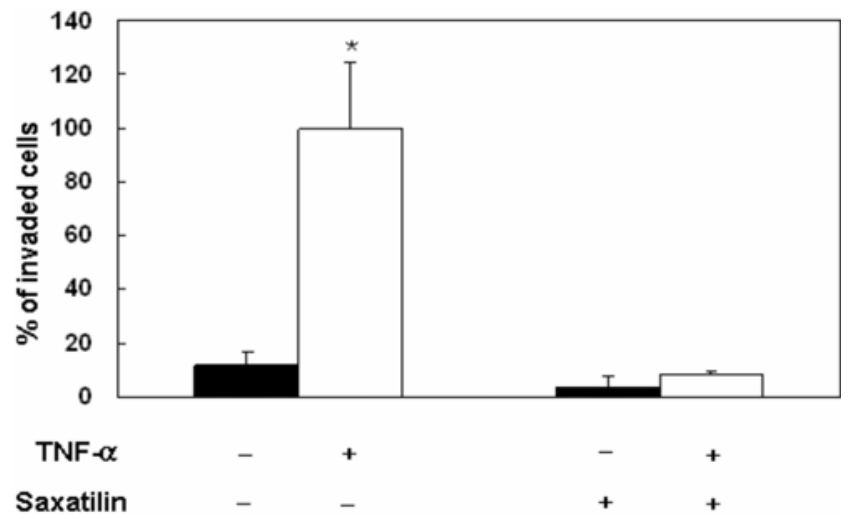

Fig. 1. The effect of saxatilin on ovarian cancer cell invasion. MDAH 2774 human ovarian cancer cell invasion was induced by treatment with TNF- $\alpha$ (10 ng). Cell invasion was suppressed by $50 \mathrm{nM}$ saxatilin. The inhibition assay was performed in a transwell plate as described in Materials and Methods. ${ }^{*} p<0.01$ compared with saxatilin treated group.

2002), a concentration over 50 times higher was used in this study. Though the experimental conditions and cells were different, it is reasonable to think that the effect of direct blocking of integrin by saxatilin on the cancer cell invasion is negligible. At nanomolar concentrations, disintegrins like saxatilin show effects distinct from those traditionally observed like integrin blocking. Alternagin-C, jarastatin, and EC3 all can induce neutrophil migration by activating signaling cascades associated with integrins (Mariano-Oliveira et al., 2003; Coelho et al., 2004). Alternagin-C and EC3 do not contain an RGD motif whereas jarastatin does. Alternagin-C and jarastatin exist as monomers, while EC-3 is a heterodimer. Despite remarkable contrasts in sequence and structure, all three induce integrin signaling which modulates cell survival, cell motility and gene expression in similar ways. Thus, it is thought that saxatilin can play diverse roles in cell movement in various cell types and under a variety of circumstances via integrin-associated signaling and regulation of gene expression.

To identify the role of saxatilin in suppressing cancer progression at the transcriptional level, RT-PCR was performed on MDAH 2774 human ovarian cancer cells after saxatilin treatment. The levels of MMP-9 mRNA decreased after saxatilin treatment in a dose dependent manner, while that of bFGF or actin were unchanged (Fig. 2A). VEGF and EGF are known to be abundant in serum of ovarian cancer patients (Baron et al., 1999; Chen et al., 1999; Nash et al., 1999). When cells were treated with TNF- $\alpha$, gelatin zymography showed that MMP-9 activity in the cell culture supernatant increased markedly. Cells treated with VEGF or EGF showed little change. However, MMP-9 activities in the cell culture supernatant of cells treated with saxatilin were significantly decreased under all conditions (Fig. 2B).

Next, we examined the effect of saxatilin on MMP-9 expression induced by TNF- $\alpha$ in ovarian cencer cells. MMP-9 activity of the cell culture medium was analyzed in gelatin
(A)

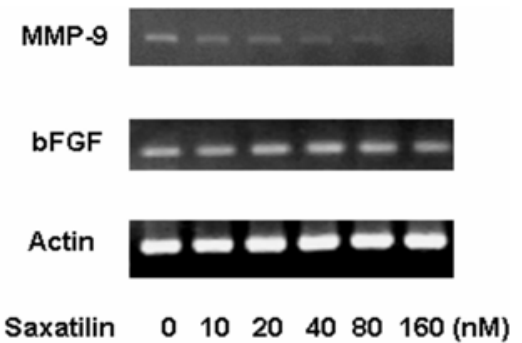

(B)

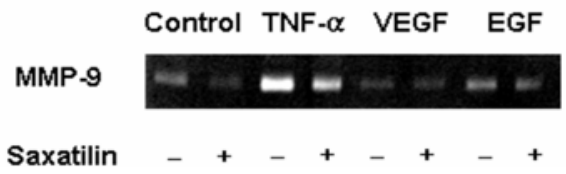

Fig. 2. MMP-9 expression in ovarian cancer cells treated with saxatilin. (A) MDAH 2774 cells were treated with the indicated concentrations of saxatilin for $4 \mathrm{~h}$. The levels of MMP-9 and bFGF mRNA were analyzed by RT-PCR. The level of human actin mRNA was used as a control. (B) Cells were treated with $10 \mathrm{ng}$ of TNF- $\alpha$, VEGF, and EGF for $24 \mathrm{~h}$ in the presence or absence of saxatilin $(50 \mathrm{nM})$. The culture media was then subjected to gelatin zymography.

(A)

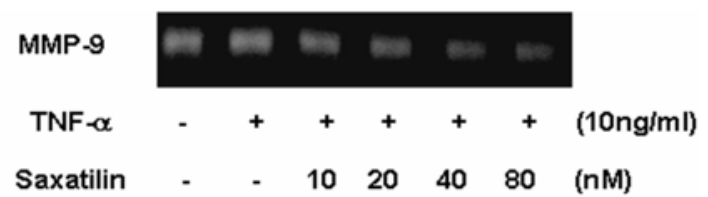

(B)

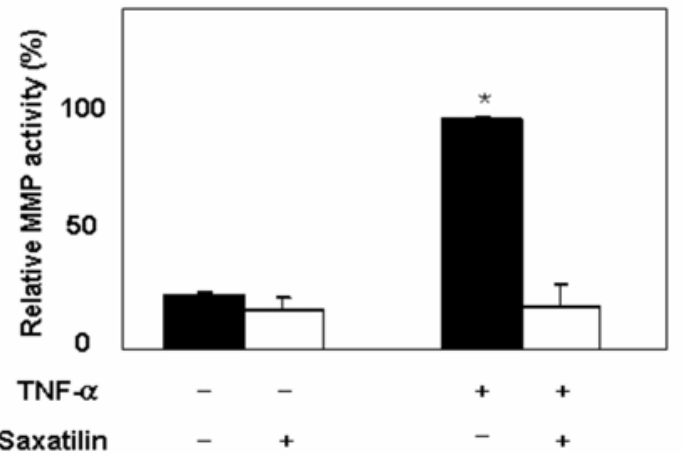

Fig. 3. TNF- $\alpha$-induced MMP-9 activity was decreased by saxatilin treatment. (A) Ovarian cancer cells were treated with 10 ng TNF- $\alpha$ and saxatilin at the indicated concentrations in serum free medium for $24 \mathrm{~h}$. The culture media was then subjected to zymography. (B) Cells were incubated with $10 \mathrm{ng}$ TNF- $\alpha$ for $24 \mathrm{~h}$ in the presence or absence of saxatilin $(50 \mathrm{nM})$. The culture supernatants were analyzed by MMP Collagenase Activity Assay Kit (CHEMICON). Each bar indicates the relative MMP activity in the cultured medium. ${ }^{*} p<0.01$ compared with saxatilin treated group.

zymography after the cells were treated with TNF- $\alpha$ for $24 \mathrm{~h}$ with or without saxatilin pretreatment for $2 \mathrm{~h}$. TNF- $\alpha$-induced MMP-9 activities were suppressed by saxatilin treatment in a dose-dependent manner in the zymogram (Fig. 3A). The 
catalytic activity of MMPs in the culture medium, including MMP-2 and MMP-9, was analyzed by ELISA. In accordance with the above data, gelatinolytic MMP activities were also increased by TNF- $\alpha$ treatment whereas the activity was greatly decreased in the presence of saxatilin (Fig. 3B). Taken together, it is apparent that TNF- $\alpha$-induced MMP-9 expression was inhibited by saxatilin treatment. However, it is interesting to note that the MMP activity was more dramatically decreased in the activity assay than in the gelatin zymography (compare Fig. 2B and Fig. 3B). Therefore, there may be another inhibitory mechanism of MMP activity besides the inhibition of MMP-9 expression. MMPs are important in diverse pathologies, including tumor progression (Bjorklund et al., 2005), thus discovering the mechanism of MMP inhibition by saxatilin could be helpful in treating various diseases.

In conclusion, we have shown that a low concentration of saxatilin decreased cell invasion through the regulation of MMP-9 activity in a human ovarian cancer cell line. These data suggest that saxatilin inhibits tumor progression in a novel manner, the molecular mechanism of which remains to be elucidated.

Acknowledgments This work was supported by the National R\&D program (Project No. 0420210-3) from the Korean Ministry of Health and Welfare, by the Korea Science and Engineering Foundation (KOSEF) through the National Research Lab program funded by the Ministry of Science and Technology (M1040000029706J000029710), and by the BK21 Project for Yonsei Biomolecule Research Initiative.

\section{References}

Baron, A. T., Lafky, J. M., Boardman, C. H., Balasubramaniam, S., Suman, V. J., Podratz, K. C., and Maihle, N. J. (1999) Serum sErbB1 and epidermal growth factor levels as tumor biomarkers in women with stage III or IV epithelial ovarian cancer. Cancer Epidemiol. Biomarkers Prev. 8, 129-137.

Bjorklund, M. and Koivunen, E. (2005) Gelatinase-mediated migration and invasion of cancer cells. Biochim. Biophys. Acta. 1755, 37-69.

Borden, P. and Heller, R. A. (1997) Transcriptional control of matrix metalloproteinases and the tissue inhibitors of matrix metalloproteinases. Crit. Rev. Eukaryot. Gene Expr. 7, 159-178.

Chen, C. A., Cheng, W. F., Lee, C. N., Chen, T. M., Kung, C. C., Hsieh, F. J. and Hsieh, C. Y. (1999) Serum vascular endothelial growth factor in epithelial ovarian neoplasms: correlation with patient survival. Gynecol. Oncol. 74, 235-240.

Choi, Y., Lee, K. W., Kwon, H. J. and Kim, D. S. (2006) Identification of immunostimulatory oligodeoxynucleotide from Escherichia coli Genomic DNA. J. Biochem. Mol. Biol. 39, 788-793.

Coelho, A. L., De Freitas, M. S., Mariano-Oliveira, A., Rapozo, D. C., Pinto, L. F., Niewiarowski, S., Zingali, R. B., Marcinkiewicz, C. and Barja-Fidalgo, C. (2004) RGD- and MLD-disintegrins, jarastatin and EC3, activate integrin- mediated signaling modulating the human neutrophils chemotaxis, apoptosis and IL-8 gene expression. Exp. Cell Res. 292, 371-384.

Davidson, B., Goldberg, I., Gotlieb, W. H., Kopolovic, J., Risberg, B., Ben-Baruch, G. and Reich, R. (2003) Coordinated expression of integrin subunits, matrix metalloproteinases (MMP), angiogenic genes and Ets transcription factors in advanced-stage ovarian carcinoma: a possible activation pathway? Cancer Metastasis Rev. 22, 103-115.

Davidson, B., Goldberg, I., Gotlieb, W. H., Kopolovic, J., BenBaruch, G., Nesland, J. M., Berner, A., Bryne, M. and Reich, R.. (1999) High levels of MMP-2, MMP-9, MT1-MMP and TIMP-2 mRNA correlate with poor survival in ovarian carcinoma. Clin. Exp. Metastasis 17, 799-808.

Ellerbroek, S. M., Fishman, D. A., Kearns, A. S., Bafetti, L. M. and Stack, M. S. (1999) Ovarian carcinoma regulation of matrix metalloproteinase-2 and membrane type 1 matrix metalloproteinase through betal integrin. Cancer Res. 59, 1635-1641.

Han, S., Ritzenthaler, J. D., Sitaraman, S. V. and Roman, J. (2006) Fibronectin increases matrix metalloproteinase 9 expression through activation of c-Fos via extracellular-regulated kinase and phosphatidylinositol 3-kinase pathways in human lung carcinoma cells. J. Biol. Chem. 281, 29614-29624.

Hong, S. Y., Koh, Y. S., Chung, K. H. and Kim, D. S. (2002) Snake venom disintegrin, saxatilin, inhibits platelet aggregation, human umbilical vein endothelial cell proliferation, and smooth muscle cell migration. Thromb. Res. 105, 79-86.

Hood, J. D. and Cheresh, D. A. (2002) Role of integrins in cell invasion and migration. Nat. Rev. Cancer 2, 91-100.

Ginsberg, M. H., Partridge, A. and Shattil, S. J. (2005) Integrin regulation. Curr. Opin. Cell Biol. 17, 509-516.

Kim, D. S., Jang, Y. J., Jeon, O. H. and Kim, D. S. (2007) Saxatilin inhibits TNF-alpha-induced proliferation by suppressing AP-1-dependent IL-8 expression in the ovarian cancer cell line MDAH 2774. Mol. Immunol. 44, 1409-1416.

Kim, K. S., Kim, D. S., Chung, K. H. and Park, Y. S. (2006) Inhibition of angiogenesis and tumor progression by hydrodynamic cotransfection of angiostatin K1-3, endostatin, and saxatilin genes. Cancer Gene Ther. 13, 563-571.

Mariano-Oliveira, A., Coelho, A. L., Terruggi, C. H., Selistre-deAraujo, H. S., Barja-Fidalgo, C. and De Freitas, M. S. (2003) Alternagin-C, a nonRGD-disintegrin, induces neutrophil migration via integrin signaling. Eur. J. Biochem. 270, 47994808.

Nash, M. A., Ferrandina, G., Gordinier, M., Loercher, A. and Freedman, R. S. (1999) The role of cytokines in both the normal and malignant ovary. Endocr. Relat. Cancer 6, 93-107.

Opdenakker, G., Nelissen, I. and Van Damme J. (2003) Functional roles and therapeutic targeting of gelatinase $\mathrm{B}$ and chemokines in multiple sclerosis. Lancet Neurol. 2, 747-756.

Cordiali-Fei, P., Trento, E., D'Agosto, G., Bordignon, V., Mussi, A., Ardigo, M., Mastroianni, A., Vento, A., Solivetti, F., Berardesca, E. and Ensoli, F. (2006) Decreased levels of metalloproteinase- 9 and angiogenic factors in skin lesions of patients with psoriatic arthritis after therapy with anti-TNFalpha. J. Autoimmune Dis. 3, 5.

Rauvala, M., Puistola, U. and Turpeenniemi-Hujanen, T. (2005) Gelatinases and their tissue inhibitors in ovarian tumors; TIMP1 is a predictive as well as a prognostic factor. Gynecol Oncol. 
99, 656-663.

Roomi, M. W., Ivanov, V., Kalinovsky, T., Niedzwiecki, A. and Rath, M. (2006) Inhibition of matrix metalloproteinase-2 secretion and invasion by human ovarian cancer cell line SKOV-3 with lysine, proline, arginine, ascorbic acid and green tea extract. J. Obstet. Gynaecol. Res. 32, 148-154.

Schmitmeier, S., Markland, F. S., Schonthal, A. H. and Chen, T. C. (2005) Potent mimicry of fibronectin-induced intracellular signaling in glioma cells by the homodimeric snake venom disintegrin contortrostatin. Neurosurgery 57, 141-153.
Sternlicht, M. D. and Werb, Z. (2001) How matrixmetalloproteinases regulate cell behavior Annu. Rev. Cell Dev. Biol. 17, 463-516.

Thommesen, L. and Laegreid, A. (2005) Distinct Differences between TNF Receptor 1- and TNF Receptor 2-mediated Activation of NFкB. J. Biochem. Mol. Biol. 38, 281-289.

Troussard, A. A., Costello, P., Yoganathan, T. N., Kumagai, S., Roskelley, C. D. and Dedhar, S. (2000) The integrin linked kinase (ILK) induces an invasive phenotype via AP-1 transcription factor-dependent upregulation of matrix metalloproteinase 9 (MMP-9). Oncogene 19, 5444-5452. 